\title{
Comparative Study of Autopsy Findings in Sickle Cell Disease (SCD) At South Eastern Tertiary Hospital, Nigeria
}

\author{
Martin Nnoli ${ }^{1}$, Nwabuko C.O ${ }^{2}$, Nnoli chinenye ${ }^{3}$, Emeka Promise ${ }^{4}$ \\ ${ }^{1}$ University of Calabar,Dept Of Pathology \& Forensic Medicine, Calabar. ${ }^{2}$ Federal Medical Centre Umuahia, \\ Dept of Haematology,Umuahia. ${ }^{3}$ University of Uyo,Dept of Paediatrics, Uyo. Akwa-ibom. ${ }^{4}$ King Faisal \\ University, College of Clinical Pharmacy, Al-Ahsa Saudi Arabia
}

\begin{abstract}
This is a presentation of comparative study of autopsy findings in sickle cell patients. A total of 403 cases were seen in Abia state, Nigeria in which autopsies were performed on 142 (35.2\%) of them. This study spanned from January 1995 -December 2000. Sickle cell disease (SCD) as is well known and is the commonest hereditary haematological disorder which is associated with increased mortality and morbidity. Many characteristic autopsy findings have been documented, some of which, though consistent, are not related to death like cardiomegaly, hepatomegaly, splenic atrophy and cholesthiasis. Common causes of death in this study include anaemic heart failure, pulmonary embolism, septicaemia, cerebrovascular accident (CVA) and meningitis. These were compared with other studies in other parts of the world. A good number of cases show no anatomical basis of death at autopsy. These then, calls for thorough autopsies to been performed and subtle causes of death for example septicaemia or biochemical abnormalities excluded appropriately. The goal is to draw awareness on the physicians on the need to do basic haematological profile of any patient that is on their care, as to exclude misdiagnosis, rate of morbidity and mortality. Also to create awareness among physicians and relatives on need of autopsy as to minimize future unexpected death from complication/crisis and enhance knowledge on both parties. From our study, anaemic heart failure was seen as the commonest cause of death which is a result of plasmodiasis. In most of the cases during emergency situations, genotypes were not known and were hence misdiagnosed. The condition of SCD was only revealed at autopsy after blood sample was analysed which showed positive for Hbss.
\end{abstract}

Keywords: Sickle cell disease, autopsy anaemia, death.

\section{INTRODUCTION}

Sickle cell disease(SCD) is the generic term for the group of haemoglobinopathies caused by the occurrence of haemoglobin $\mathrm{S}$ (Hbs) in the homozygous form -sickle cell anaemia (Hbss) or as the heterozygous combination of Hbs with another abnormal haemoglobin such as Hbsc or beta -thalassaemias (Hbsb-thal). Haemoglobinopathies are the commonest inherited disorders worldwide and SCD shows an important proportion of these. The clinical features are variable and relate to diverse factors, ranging from climate, socioeconomic, haemoglobin level, level of fetal haemoglobin and the type of abnormal haemoglobin that accompanies the $\mathrm{Hbs}$ in the heterozygous form ${ }^{1}$. Inspite of much improvement in treatment, life survival is still associated with high morbidity and mortality. The findings at autopsy are variation of features which may or may not be directly connected to death. This is not only due to few autopsy studies but lack of interest of populace for autopsy to be carried out. The fact remains that the relatives will ignore any further studies having known the patient genotype. This study reviews the autopsy findings that are seen in SCD showing major morphological changes; importance and frequency of those lesions that possibly lead to death ${ }^{1}$. This is to evaluate the pathological autopsy findings in our Centre and compare them with that of other places as to create awareness among the physicians and relatives/public and to minimize future unexpected death from complications/crisis from SCD.

\section{METHODOLOGY}

The study covers a period of five years (January 1995 -December 2000) and it is a study of cases of autopsy carried out in a 150 bedded tertiary hospital of Abia State- Nigeria. A total of 403 case notes of patients were examined but in only $142(35.2 \%)$ were consent given for an autopsy to be done. The hospital is the only referral hospital that caters for all strata of patients. The respective records were reviewed and causes of death were stated using the simple random method. At the end, total causes of death in the groups were recorded and percentage of occurrence noted. These were then compared with studies in other parts of the world where such data were available. 


\section{PATHOLOGICAL (MACROSCOPIC) FINDINGS IN SCD}

There are general external features that are specific physical features which are consistent and characteristics of SCD and are seen at necropsy. These are as a result of chronic haemolysis and vascular occlusion on presence of sickled erythrocytes. These are seen in the brain area as hypareamia and encephalomalacia thus showing some areas of recent infarction. Neurological complications are not so common but affect up to $25 \%$ of patients, majority due to cerebral vascular accidents (CVA) ${ }^{2}$ They can be seen at young and aged which may be either due to intra cerebral infarction or subarachnoid haemorrhage ${ }^{3,4}$. Death arises frequently due to infarction than from CVA5. Majority of death in SCD arises from intracranial (berry) anuersyms and subarachnoid haemorrhage ${ }^{4}$.The anuresyms here are unusual as a result of multiple fast and arises from unusual sites ${ }^{2}$. A $60 \%$ incidence of multiple aneurysms was seen in one series, with a patient having as many as five aneurysms and being found at ophthalamic and anterior choroidal arteries which are obviously unusual sites ${ }^{6}$. Meningitis specifically affects younger patients and is often bacterial in nature (streptococcus pneumonia) ${ }^{3,7}$. The brain is often oedematous, with purulent exudates varying in amount and extent of spread on the convexities. This type of meningitis is uncommon in adult but if it occurs it has a high risk of mortality ${ }^{8}$. Most children have cardiomegaly at first 5 years of life with adults having biventricular hypertrophy ${ }^{9}$. Myocardial infarction in the absence of artheriosclerotic coronary artery disease has been documented, with ischaemia being attributed to combinations of anaemia, vasospasm and platelet thrombi ${ }^{10,11}$. Right heart failure has been seen in patient with pulmonary hypertension due to multiple thrombotic occlusion of small and medium - sized pulmonary arteries ${ }^{12,13}$. Cardiac dysfunction in SCD can be explained by adverse effects of concurrent disease on the diminished cardiac reverse of chronic anaemia ${ }^{9}$. The spectrum of findings in the lungs ranges from bronchopneumonia, pulmonary thrombo-embolism /thrombosis, necrotic bone marrow emboli to fibrosis ${ }^{10}$. The "acute chest syndrome" refers to the clinical syndrome associated with acute pulmonary pathology in SCD. The term has invoked a certain amount of diagnostic confusion. A study done in Jamaican by Thomas et al ${ }^{7}$ reported that acute chest syndrome was used to encompass disease due to pneumonia, pulmonary embolism or both (Table 2). Whereas in the United Kingdom, it denoted acute pulmonary failure without aetiology or where it occurs, it was considered to be minor ${ }^{14}$ (Table 3 ). In the USA, it was seen as chest pain, fever and pulmonary infiltrate on chest x-ray ${ }^{15,16}$ (Table 4). In older patients, findings included scarring and shrinking of the kidneys with coarsely granular subscapular surfaces, papillary necrosis and gross distortion and also scarring of the pelvic-calyceal system. There was also progressive partial or total fibrosis of the glomeruli with age ${ }^{20}$. It is well documented that duodenal ulcers have a higher prevalence rate in SCD than in general population, but this has not been established by age and sex or matched with controlled studies and warrants more investigation ${ }^{20}$. There is hyperplasia of bone marrow with response to increased erythropoietic demand, thus affecting vertebral bodies giving a characteristic flattering and increased width to height ratio. It further presents as upper and lower vertebral bodies biconcave nature resembling 'fish vertebra $^{21}$. Osteomylitis has been shown to results from salmonella infection with over $70 \%$ haematogenous type caused by salmonellae ${ }^{1}$. The studies relating to causes of death in SCD have been very few. In our referral centre in Abia state, little or none has been done because of a lot of factors arising from the patients and the researchers. Results extracted from 403 case notes (Hbss)from 1995 -2000 and 142 had autopsies showing the commonest cause of death to be anaemic heart failure, followed by pulmonary embolism, septicaemia and cerebral vascular accidents(CVA) and also observd by other workers ${ }^{22}$. Studies in the Caribbean (Jamaica) from five centres where 241 patients were studied, 154 had autopsy done ${ }^{7,19}$, whereas in the UK studies were from 18 patients (13 Hbss, 4Hbsc), with 14 autopsied $^{13}$ (tables 2 and 3). The USA had three studies totaling 356 patients (302 Hbss, 34Hbsc) and 187 autopsied $^{3,23,24}$ (Table 4). Also in the Caribbean (Jamaica) and in the UK common cause of death was reported as acute chest syndrome (ACS) but in the US, this was the second cause SCD death. Thomas et al $^{7}$ noted that pulmonary embolism involvement as the commonest cause of ACS in older aged groups. Infection is another cause, presenting as meningitis, septicaemia and pneumonia. Also renal failure was seen as a feature in adulthood in both groups (Caribbean and USA, tables 2 and 4). A number of deaths results from cerebrovascular accidents in all the studies. An analysis of age distribution at death in my centre Abia showed the highest mortality to be in first 3 years. This is fairly comparable to 5 years obtained from Jamaica with the highest mortality in single year being first year and commonest cause of death was $\mathrm{ACS}^{7}$.However, this is less frequent cause in the UK and USA studies. In USA, one of the studies showed peak incidence at 1 and 3 years, major factor being infection from pneumococcal septicaemia ${ }^{3}$.From the tables, it showed that 5\% [7] and 22\% [22] of patient had no anatomical cause of death, although in some cases death from painful crises without any other explanation has led to suggestion that painful crisis may be a cause of death in sickle cell disease ${ }^{23,24}$.

\section{DISCUSSION/CONCLUSION}

Generally, a lot of gross pathological abnormalities could be seen at autopsy in patients with sickle cell disease. These pathologies range from cardiomegaly, hepatomegaly to cholelithiasis and are regular features. 
However, these do not denote the cause of death. Most of the crisis patients goes in early life are usually bone pain crisis and sequestration. The later seems to be the commonest cause of death at this early age. In later life, acute chest syndrome and organ failure like renal are main causes of death. In some cases, no cause of death could be evaluated in both clinical and anatomical cases in autopsy. It is however important to note that available highly sophisticated investigation tools ranging from MRI, CT-scan will be very helpful in detecting possible embolism or rupture of vessels that could not be seen by former procedures. In our study, it is believed that anaemic heart failure results from infection due to plasmodiasis ${ }^{25}$. Also lack of adequate knowledge of the disease entity plus a lot of superstitious beliefs are factors that affect proper management of SCD in our centre. Also failure of early intervention in patient with SCD contributed to sudden deaths of this group of patient. This is because in about $60 \%$ of cases haematological genotype are not known until after autopsy. This is important that relatives of patients grant consent for autopsy to aid the physicians in effective management of future patients.

\section{REFERENCES}

[1]. Davies SC, Brozoic M. The presentation, management and prophylaxis of sickle cell disease. Blood Rev.1989;3: 29 -44.

[2]. Preul MC, Cerdes F, Just N, Mohr G. Intracranial aneurysms and sickle cell anaemia; multiplicity and propensity for the vertebrobasilar territory. Neurosurgery $1998 ; 42: 971-978$

[3]. 3.Leikin SL, Gallagher D, Kinney TR, Sloane D, Klug P, Rida W. Mortality in children and adolescents with sickle cell disease. Peditrics 1989; 84:500-508.

[4]. Bulkaran B, Char G, Morns JS, Thomas PW, Serjemt GR. Stroke in a cohort of patients with homozygous sickle cell disease. J padiator $1992 ; 120: 360-366$.

[5]. Ohene-Frempong K, Weiner SJ, Sleeper LA et al. Cerebrovascular accidents in sickle cell disease : rates and risk factors. Blood 1998; 91: 288-294.

[6]. Oyesiku NM, Barrow DL, Eckman JR, Tindall SC, colohan ART. Intracranial aneurysms in sickle cell anaemia : Clinical features and pathogenesis. Journal of neurosurgery 1991; 75: 356-363.

[7]. Thomas AN, Pattison C. Causes of death in sickle cell disease in Jamaica. Br. Medical Journal 1982; 285;633-635.

[8]. Olopoenia et al. Pneumococcal sepsis and meningitis in adults with sickle cell disease. South Medical Journal 1990; 83: 10021004 .

[9]. Gerry JL, Burkley BH. Clinicopathologic anaylsis of cardiac dysfunction in 52 patients with sickle cell anaemia. AM J Cardiol 1978; 42:211-216.

[10]. Darbari, D. S., Kple-Faget, P., Kwagyan, J., Rana, S., Gordeuk, V. R. and Castro, O. (), Circumstances of death in adult sickle cell disease patients. Am. J. Hematol., 2006: 81: 858-863.

[11]. Martin CR, Johnson CS. Myocardial infarction in sickle cell disease. Journal of Natl Med Assoc 1996;88: 428-432.

[12]. Collins FS, Orringer EP. Pulmonary hypertension and Corpulmonale in sickle cell haemoglobinopathies. AM J Med 1982; 73: 814821 .

[13]. De Castro, L. M., Jonassaint, J. C., Graham, F. L., Ashley-Koch, A. and Telen, M. J. (2008), Pulmonary hypertension associated with sickle cell disease: Clinical and laboratory endpoints and disease outcomes. Am. J. Hematol., 83: 19-25.

[14]. Gray A, Anionwu EN. Patterns of mortality in sickle cell disease in United Kingdom. Journal of clinical pathol $1991 ; 44$ :459-463.

[15]. Haynes J, Kirkpatrick MB. The acute chest syndrome in sickle cell disease. : Am J Med. Sci 1993; 305: 326-330.

[16]. Castro O et al. Acute chest syndrome in sickle cell disease :Incidence and risk factors. Blood 1994; 84 :643-649

[17]. Powers D, Weildman JA et al. Sickle cell chronic lung disease: Prior morbidity and the risk of pulmonary failure. Medicine 1988, 67:66-77.

[18]. Schubert TT. Hepatobiliary system in sickle cell disease. Gastro enterology 1986; 90:2013- 2021

[19]. Webb DK et al. Gall stones in Jamaican children with the homozygous sickle cell disease. Arch disease child 1989; 64:693 -696.

[20]. Morgan AG, Shah DJ, William W. Renal pathology in adults over 40 with sickle cell disease. West Ind Med J $1987 ; 36: 241$-250.

[21]. De Caestecker JS et al. Duodenal ulcer in sickle cell disease. Gut 1989; 30:1657 -1658.

[22]. Westman MP et al. "Fish vertebrae' homocystinuria and sickle anaemia. JAMA 1974; 230:261 -262.

[23]. Graham Jason K, Mosunjac Marina, Hanzlick Randy L, Mosunjac Mario M. Sickle Cell Lung Disease and Sudden Death: A Retrospective/Prospective Study of 21 Autopsy Cases and Literature Review. American Journal of Forensic Medicine \& Pathology. 2007 (28); 168-172.

[24]. Parfrey NA, Moore W et al. Is pain crisis a cause of death in sickle disease? Am J Clin Pathol 1985; 209 -212.

[25]. Platt SS, Brambilla DJ et al. Mortality in sickle cell disease. Life expectancy and risk factors for early death. N. Engl. J Med 1994; 330: $1639-1644$.

[26]. Manci, E. A., Culberson, D. E., Yang, Y.-M., Gardner, T. M., Powell, R., Haynes, J., Shah, A. K., Mankad, V. N. Investigators of the Cooperative Study of Sickle Cell Disease (), Causes of death in sickle cell disease: an autopsy study. British Journal of Haematology; 2003: 123: 359-365.

TABLE 1 CAUSES OF DEATH IN SICKLE CELL DISEASE IN ABIA -NIGERIA CAUSES $\mathrm{n} / \%$

\begin{tabular}{l}
\hline 1. Anaemic heart failure. \\
2. Meningitis. \\
3. Pulmonary Embolism. \\
4. Septicaemia. \\
5. Cerebral Vascular accident.
\end{tabular}

$102 / 25.3 \%$

$69 / 17.1 \%$

$84 / 20.8 \%$

$76 / 18.9 \%$

$72 / 17.9 \%$

$\mathrm{n}=$ number of autopsied cases 


\section{TABLE 2 CAUSES OF DEATH IN SICKLE CELL DISEASE IN JAMAICA}

\begin{tabular}{lll}
\hline \multicolumn{2}{l}{ CAUSES } & $\mathbf{n} / \mathbf{\%}$ \\
\hline 1. & Acute chest syndrome. & $60 / 30 \%$ \\
2. & Acute splenic sequestration. & $23 / 12 \%$ \\
3. & Renal Failure. & $21 / 11 \%$ \\
4. & Meningitis. & $18 / 9 \%$ \\
5. & Cerebral Vascular accident. & $14 / 7 \%$ \\
6. & No anatomical cause of death & $9 / 5 \%$ \\
\hline
\end{tabular}

$\mathrm{n}=$ number of autopsied cases

TABLE 3 CAUSES OF DEATH IN SICKLE CELL DISEASE IN UNITED KINGDOM

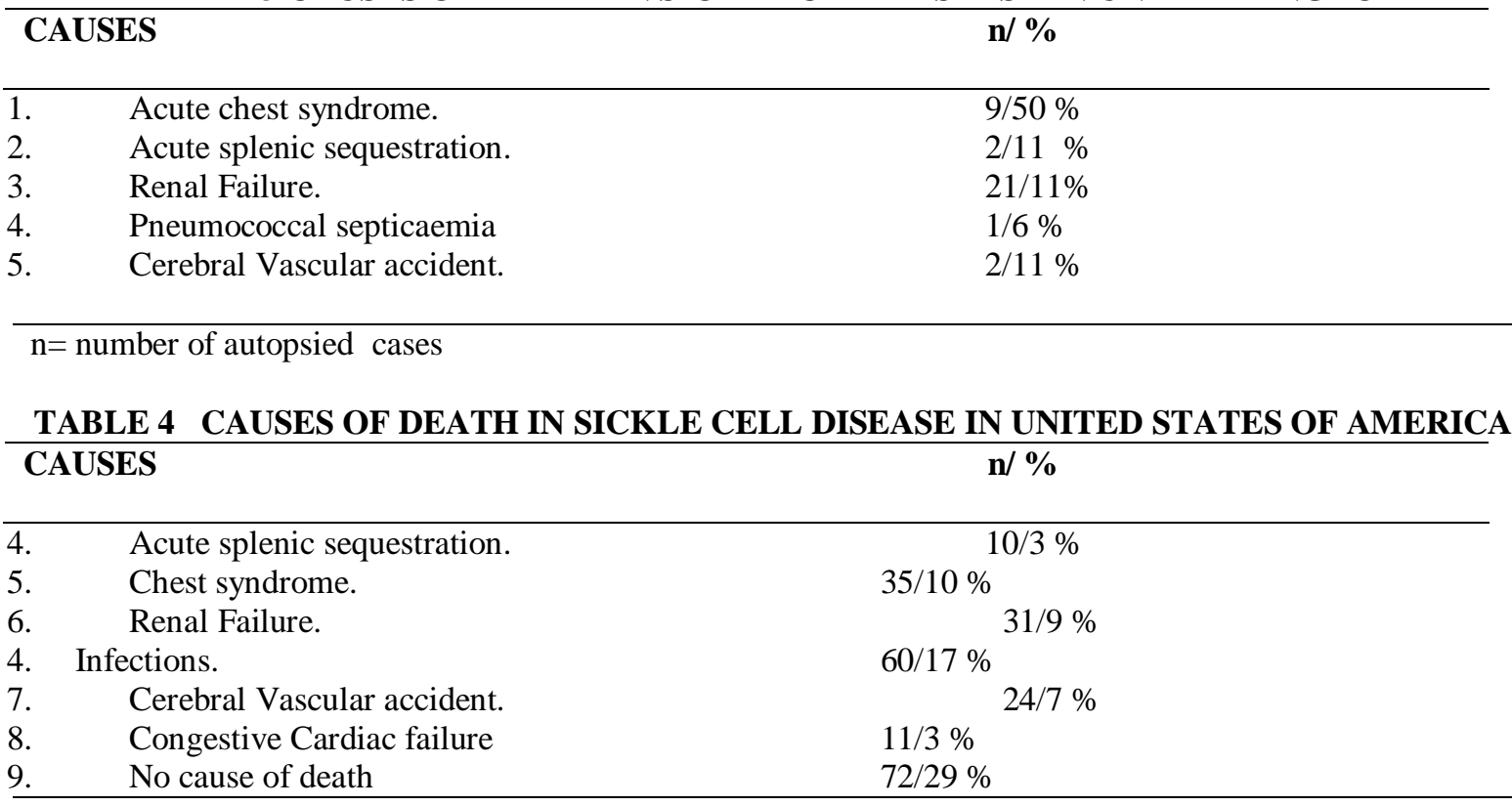

$\mathrm{n}=$ number of autopsied cases 